\title{
Correction to: Associations Between Student Engagement and Drug Use: Age and Gender Comparisons Using the California Healthy Kids Survey
}

\author{
Lawrence M. Scheier ${ }^{1} \cdot$ Martin Komarc $^{2}$ \\ Published online: 16 November 2020 \\ (C) California Association of School Psychologists 2020
}

Correction to: Contemporary School Psychology https://doi.org/10.1007/s40688-020-00331-8

The original article has been revised to correct the presentation of the tables.

Publisher's Note Springer Nature remains neutral with regard to jurisdictional claims in published maps and institutional affiliations.

The online version of the original article can be found at https://doi.org/ $10.1007 / \mathrm{s} 40688-020-00331-8$

Lawrence M. Scheier

scheier@larsri.org

Martin Komarc

komarc@volny.cz

1 LARS Research Institute, Inc., 15029 N. Thompson Peak Parkway, Suite B111-443, Scottsdale, AZ 85260, USA

2 Faculty of Physical Education and Sport, Department of Kinanthropology and Humanities, Charles University in Prague, Prague, Czech Republic 